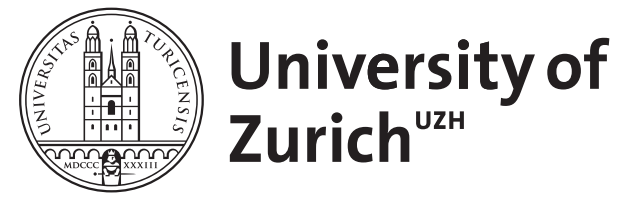
Archive

University of Zurich

University Library

Strickhofstrasse 39

CH-8057 Zurich

www.zora.uzh.ch

Year: 2020

\title{
Doing things with quotes: introduction
}

Fetzer, Anita ; Weiss, Daniel

DOI: https://doi.org/10.1016/j.pragma.2020.01.001

Posted at the Zurich Open Repository and Archive, University of Zurich

ZORA URL: https://doi.org/10.5167/uzh-215943

Journal Article

Accepted Version

\section{(c) $(\oplus \Theta \Theta$}

The following work is licensed under a Creative Commons: Attribution-NonCommercial-NoDerivatives 4.0 International (CC BY-NC-ND 4.0) License.

Originally published at:

Fetzer, Anita; Weiss, Daniel (2020). Doing things with quotes: introduction. Journal of Pragmatics, 157:84-88

DOI: https://doi.org/10.1016/j.pragma.2020.01.001 


\title{
How to do things with quotes
}

\author{
Introduction \\ Anita Fetzer (University of Augsburg, Germany) \\ Daniel Weiss (University of Zurich, Switzerland)
}

Ordinary-language research has changed the focus from investigating language as a rigid system to How to do things with words (Austin 1976) in context. As a result, the use of language - and other semiotic systems - has been anchored firmly to participants, or model persons (Brown and Levinson 1987) imbued with consciousness, rationality, intentionality and facewants and face-needs. For the language-use-as-communicative-action paradigm performing speech acts in context means using language in context strategically to achieve particular goals. The change in perspective from the truth or falsity of a proposition to performing speech acts in context, and consequently from truth conditions to felicity conditions meant a shift to a more dynamic action-based paradigm. It is not only the speech-act-as-a-whole and its constitutive acts, viz. propositional acts and illocutionary acts, that have been assigned the status of communicative action, but also the constitutive acts of proposition (or locution), that is the linguistic acts of reference and predication constituting the propositional act (Searle 1969), and sense and reference constituting the locutionary act (Austin 1976). Felicity conditions and convention or standardized illocutionary indicators regulate what a particular speech act in context counts as.

Focusing on the social role of speech acts in discourse, Sbisà (2002) argues for their contextchanging role, shifting the focus from the production of speech acts to their reception and interpretation. Accordingly, speech acts do not only have cognitive effects in that their meaning and force are recognized by the hearer, but also social effects, such as assignments of obligations or entitlements. Against this background, felicity conditions are specifications of context. More recently, speech acts have been adapted to a discourse-based perspective, considering not only speaker and addressee as constitutive parts of the communicative exchange but rather multi-party interactions. As a consequence of the pluralism of participation with speakers being both producers and recipients in a communicative exchange, and vice versa, considering also multi-party interactions with more than one speaker and more than one recipient, the status of utterances as the linguistic realisation of one type of speech act only has been challenged. Speech acts in discourse carry the potential of performing a plurality of illocutionary acts (cf. Witek 2015).

In How to do things with words Austin discusses six types of speech acts. One type of speech acts with a discursive function is the expositive. Expositives have the function of making plain how utterances fit into the course of an argument or conversation, of how speakers are using words, and of what they intend their words to count as. Possible realisations of expositives are 'I turn next to', 'I quote', 'I cite', 'I recapitulate', 'I repeat that', 'I illustrate', 'I deny' or 'I mention that': "Expositives are used in acts of exposition involving the expounding of views, the conducting of arguments, and the clarifying of usages and of references" (Austin 1976:161), and are thus assigned a metacommunicative function as "the expositive is the clarifying of reasons, arguments, and communications" (Austin 1976:163). Expositives are different from classical speech acts because the conventional illocutionary effect brought about by an 
expositive is not a change in the world, but rather a speaker comment on how s/he intends the speech act to be taken: "In performing an expositive illocutionary act, the speaker makes manifest how illocutionary force and locutionary meaning are intended to be contextualised discursively in context $\mathrm{C}$, at a particular stage in discourse. In doing so, the speaker as the addresser of the illocutionary act makes manifest her perlocutionary intention of producing a perlocutionary object or sequel" (Oishi and Fetzer 2016: 54). For quotations as one type of expositives this means that the speaker who performs the illocutionary act of quoting, the quoter, makes manifest that the illocutionary force of bringing a quotation into a discourse is different to the original illocutionary force of the quoted, and s/he makes manifest that the locution of the expository act of quotation is not necessarily her/his own locution, but rather a locution that has been performed in a different context, or one which is of purely hypothetical nature, as is the case with hypothetical quotations or hypothetical discourse (Tannen 1989). This holds for both previously uttered speech acts and previous mental acts which may both be brought into an ongoing discourse and assigned the status of an object of talk. The 'meta' status of quotations is not only reflected in their classification as an expositive speech act type, which has been classified as a higher-level speech act (Oishi and Fetzer 2016), but also in relevance theory's classification of quotation as a type of metarepresentation.

Metarepresentation "involves a higher-order representation with a lower-order representation embedded inside it. The higher-order representation is generally an utterance or a thought" (Wilson 2012: 232). Quotation as a type of metarepresentation "can be analysed in terms of a notion of representation by resemblance" (Wilson 2012: 243; original emphasis), and "resemblance involves shared properties" (Wilson 2012: 244). The issue of resemblance is also reflected in the classification of quotation as direct, indirect and mixed quotation, for instance, and it can be exploited in the case of fake quotes which are brought into the discourse with the presumption of having been produced in accordance with the Gricean (super) maxim of quality. As regards their function in discourse, the quantity of features of resemblance is considered to reflect different degrees of reliability of the quoted content and its force. While direct quotation is generally seen as a verbatim representation and thus requires a full set of features of resemblance with its original representation (cf. Brendel, Meibauer and Steinbach 2011), Wilson considers 'resemblance' as a scalar concept. For her, direct quotation is not a verbatim metarepresentation but only a metarepresentation with "merely (...) to some degree." (Wilson 2012: 244): "direct quotation (...) increases the salience of formal or linguistic resemblances" (Wilson 2012: 244). Resemblance is thus not solely form-based but rather interpretative. That is to say "[i]nterpretive resemblance is resemblance in content: that is shared implications." (Wilson 2012: 244). This also encompasses quotations rendered fully or partly (by code switching) in a different language than the one of the ongoing discourse. Moreover, it allows to link intertextual allusions with core (direct) quotations by a double scale: the fewer formal and interpretative resemblances the case at hand shares with the corresponding original representation, the more it may count as an allusion. In terms of linguistic form, this implies truncation, partial substitution and/or extension of the original discursive excerpt; such an understanding also includes word plays and puns. As for content, allusions may not only evoke individual texts (literary works, jokes, songs, etc.) but also an entire textual genre, such as fairy tales or obituaries.

In what follows, we suggest to distinguish between "fresh" quotations which are metarepresentations of utterances, hypothetical discourse and fake discourse which the quoter 
presumes are previously unknown to the addressee(s) or audience, and "canned", ready-made quotations which the quoter presumes most recipients are familiar with. The latter category comprises a wide range of different types of sources, for instance proverbs, aphorisms, slogans, formulaic language (such as "exit left", "made in China"), canned jokes, quotations from literature, films, TV, pop music, advertisements, etc. The boundary between these two categories is fuzzy and may change with new linguistic material which may count as a canned quotation. This is because many fresh quotations spread rapidly through the media; by frequent citation they turn into generally known stock expressions with their original source sometimes not being identifiable any longer. Social media accelerate this process even further, which may be best illustrated by memes (cf. Yus 2018, for identity-related issues). Many characteristics ascribed to quotations in the literature, such as Bublitz (2015), consider only fresh quotations: they all mention the commitment to verbatim reproduction of the quoted for direct quotation and the - more or less - exact reference to the source. Canned quotations tend to vary considerably in form, and their source is general knowledge and thus part of the common ground or cultural memory; the source may even be anonymous. As part of the common stock of prefabricated constructions, the use of canned quotations invites variation in its linguistic presentation with respect to various kinds of word play and allusions (Lennon 2004). The latter may be defined as a graded term located towards the end of the scale extending from core (direct) quotations to allusions: the fewer formal and interpretative properties the given case has in common with the original utterance, the more it will count as an allusion, and the more it will lend itself to humoristic, ironic or polemic effects. Unlike fresh quotations, which usually stem from contemporary sources, canned quotations are not bound to any temporal horizon but may import material from the Bible, Greek philosophers, classic literature, received folk wisdom, etc.

Relevance theory defines quotation as metarepresentation, metarepresenting not only the quoted, that is the utterance(s) or selected excerpts thereof, but also its discursively contextualised illocutionary force. The metarepresentation of participants, content and force has been referred to as entextualisation ${ }^{1}$ (Fetzer 2015) in discourse pragmatics, and frequently other relevant contextual coordinates are also entextualised, for instance participation format; that is, source and their participation status as animator, author and/or principal, and recipient and their status as ratified or unratified addressee, or target (Goffman 1981), for instance - and physical, temporal and discursive setting, which may have been implicit in the original production. In the case of canned quotations, many of these components, especially participation format and local and temporal setting are not of relevance to the stage where they occur in the discourse. Moreover, not all of the constitutive parts of a quotation can be metarepresented. This is particularly true for indexicals, metaphors or - in the case of spoken discourse - prosodic, gestural and facial cues. From a context-based perspective, quotations are a challenge to the analyst because the indexicals used in the quoted discursive excerpt cannot

\footnotetext{
${ }^{1}$ The use of 'entextualisation' shares Park and Bucholtz's (2009: 489) conceptualisation of entextualisation in terms of "conditions inherent in the transposition of discourse from one context into another", while additionally considering explicitly entextualisation in local contexts, in particular when participants assign an unbounded referential domain, such as an unbounded event, the status of a bounded referential domain or a bounded event or when they particularise a general event or entity. In the context of Prime Minister's Questions, for instance, the leader of the opposition, Jeremy Corbyn, quotes a member of the public, Steven, whose position in society is entextualised as someone "who works for a housing association: "I have a question from Steven, who works for a housing association. He says that the cut in rents... " (Prime Minister's Questions 16.09.2015).
} 
be bound by the quoting context (cf. Brendel, Meibauer and Steinbach 2011). Consequently, it is not only indirect quotation and free indirect speech, which are referentially opaque, but also direct quotation.

Fresh quotations thus display a higher degree of explicitness than their original representation; this is because it is not only the quoted which is imported into the ongoing discourse, but also the original participation format entextualised in source as well as other participants, such as addressee(s) or audience, and the original physical, temporal and discursive setting. This is not the case with canned quotations, where a lot of contextual information remains unexpressed or is not relevant at "the stage at which it occurs" (Grice 1975:45). In discourse, the quoter may also entextualise their interpretation of the source's communicative goal and the source's perlocutionary effects.

\section{Quotations in discourse}

Quotations are a ubiquitous phenomenon in discourse, especially in mediated genres. They occur in various types of discourse across different contexts and with different degrees of formality, for instance academic discourse, legal discourse, in particular cross-examination, mediated monologic and dialogic political discourse, but also in mundane everyday communication, especially personal narratives. They vary considerably in length and may also include other quotations and whole dialogic, if not multilayered sequences. They have been examined in linguistics, pragmatics, discourse analysis and conversation analysis across languages, contexts and cultures, filtering out different kinds of formatting with respect to quoter, source, quotative and quoted, and assigning different degrees of subjectivity and different communicative functions to the formats. Canned quotations allow for a maximum of variation: the original wording may be truncated, expanded or partly replaced by new components.

Quotations have been classified as direct, indirect, mixed, mixed type, focussing and hypothetical quotations, and more recently as fake quotes, adapting to the contextual constraints and requirements of computer-mediated discourse.

Direct quotations are analysed as metarepresentations of verbatim representations of what has been said. In written language they are signalled with quotations marks and in spoken language with quotatives, such as 'I quote' or 'they said'. In spite of the quoter's entextualisation of the illocutionary force of the source, direct quotation is generally considered to display the lowest degree of subjectivity, since it represents the quoted in a more or less verbatim manner, dependent on the genre at hand. Both fresh and canned quotations utilise this format.

Indirect quotations represent what has been said from the quoter's perspective and thus display some degree of subjectivity, which is reflected in deictic and temporal shifts. The quoter's interpretation of the force of the quoted may be neutral (e.g., they 'said'), or it may be subjectively coloured (e.g., they 'claimed' or even 'made the accusation'). For instance, indirect quotation is generally seen as expressing a higher degree of subjectivity than direct quotation, as the former encodes the quoter's interpretation of the source's illocutionary force while direct quotation has been classified as a verbatim speech report which - because of that - displays a 
higher degree of objectivity. ${ }^{2}$ As is the case with direct quotation, both fresh and canned quotations use this format.

Mixed quotations comprise components of both direct and indirect quotation and thus also metarepresent the quoter's interpretation of the illocutionary force of the source. In mixed quotations, the quoter expresses detachment from the indirectly formatted parts of the quoted while at the same time foregrounding the directly quoted part, whose appropriateness, if not validity may be queried, sometimes ironically. Both fresh and canned quotations may be formatted as mixed quotation.

Mixed type of quotation is also referred to as free indirect speech, that is a hybrid format in which the quoted does not undergo any deictic shifts in spite of a past-tense formatted quotative. It is also subjectively coloured and used strategically to express immediacy and relevance to the here-and-now. This format is only used for fresh quotation, as is the case with focussing quotations.

Focussing quotations exploit the linguistic formatting of direct quotation and adapt the entextualisation of the quotative to the question-and-response sequence of dialogic discourse, furnishing the quotative with a pseudo-cleft-like focussing construction, thereby foregrounding the quoted. Like direct quotation, focussing quotation is generally considered to display a low degree of subjectivity, since it represents the quoted in a verbatim manner.

Hypothetical - or fictive - quotations exploit the linguistic formatting of focussing, direct and indirect quotations, but realise the quotative in irrealis mood - referring to hypothetical future or past, thus metarepresenting a hypothetical communicative act or even a whole dialogic exchange. They may include canned quotations but canned quotations alone cannot constitute hypothetical quotations. Fake quotations could be considered a subtype of hypothetical quotations with intentionally misleading content and false attribution to a source. This in turn has to be distinguished from simple unintentional misquoting. On the other hand, fake quotations are different from all other types of quotations on account of their insincere motivation. Fake quotes may utilize the formatting of direct, indirect, mixed and focusing quotation as well mixed type of quotation. Fake quotes count as fresh quotations.

Fresh and canned quotations may further be distinguished with respect to the participation format as self- and other-quotation. This may be further refined by the adaptation of the production and reception format, and social and interactional roles (Goffman 1981; Levinson 1988), in particular footing and the parameters ' + --ratified'. For direct and focussing quotation, the quoter adopts the footing of animator, i.e. the speaking machine, and of some kind of mediated principal, while the source is author, i.e. the author of the words that are being spoken / read and who has selected and encoded or implicated the sentiments, and principal, i.e. someone whose position is established, whose beliefs have been told, and who is committed to what the words say. For indirect quotation, mixed quotation and mixed type of quotation, the quoter is animator and mediated author and principal, while the source is author and principal. Quotations do not only import context into an ongoing discourse and assign it the status of an object of talk, indicating that the quotation is relevant to a particular communicative goal at that particular stage in discourse. They are intended to secure the joint construction of discourse common ground (Fetzer 2007) and thus felicitous communication between the potential

\footnotetext{
${ }^{2}$ This issue is of particular importance to the translation of quotations (cf. Schäffner and Bassnett (2010), in particular their introductory chapter).
} 
participants, spanning from those involved in the direct face-to-face interaction to other less determinate audiences in mediated discourse. Quotations thus fulfil an important interpersonal function: they contribute to the positioning of quoter, quoted, source and recipients vis-à-vis each other. They relate quoter, quoted and source to other participants in the communicative exchange, for instance direct addressees, readers or media audiences, through setting out common ground relevant to the ongoing discourse. This relational nature of quotations holds for all types of quotation, irrespective of their source, and irrespective of their linguistic formatting. In media discourse, quotations and their metadata may also be utilised to secure the discourse common ground between the media-frame participants and the mediated audience, thereby supporting the construal of discourse coherence, and in computer-mediated discourse, the metadiscursive device of hyperlinks invites participants to access relevant background information.

Quotations may fulfil various functions in discourse, ranging from argumentation to interpersonal functions, for example attacking / supporting Other. When used in argumentation, they import evidence by other participants or by Self into an ongoing discourse, which may count as arguments for or against some proposed action, statement or claim. Canned quotations are more likely to involve arguments from authority, although this may also be questioned or contested. Quotations may display anaphoric reference to some prior discourse or sometimes a prior stretch of the same discourse, recycling specific discursive excerpts and following up on them with respect to their validity and relevance to a current stage in the discourse. Fictive quotations cover a range of additional functions: besides serving argumentative and interpersonal purposes, they may, for example, contribute to the expression of interpersonal involvement, make manifest actors' mental states and feelings or allow for the co-construction of stories, arguments etc. The felicitous communication of allusions often requires profound cultural knowledge but offers a significant enhancement of common ground and rewarding benefits from playful creativity.

This special issue addresses the question of how to do things with quotes across different contexts and discourse genres, and across different languages. All papers adhere to the premise that participants use fresh and canned quotations in their different formats strategically to achieve particular goals in discourse; paper (1) contrasts Hebrew and French data, (5) and (6) are based on Russian data, (7) involves Greek data, and all remaining papers discuss English material.

The contributions are ordered according to the main types distinguished above: three contributions deal with fresh quotations, two papers address the use of canned quotations and their associative potential, the next paper covers both hypothetical and canned quotations (proverbs), the following one is exclusively dedicated to hypothetical quotations, and the last one examines fake quotations. The first paper focuses on the strategic use of the quotative claim in online commenting, papers 4, 6, 7 and 8 discuss the strategic use of quotations in mediated political discourse, including both non-elite and elite political discourse. The rest of the papers analyse the strategic use of quotations in ordinary conversation $(5,7)$ and the strategic use of quotations in the participatory discourse of Wikipedia (3).

(1) Elda Weizman examines the strategic uses of the discursive pattern 'claim+ indirect quotation in quotation marks' in French and Hebrew journalistic discourse. She argues that this pattern is mostly used to convey mild reservations, albeit a certain ambiguity pertaining to its 
affiliation with two paradigms of metarepresentations - forms of quotations on the one hand, and of ironic reservations on the other. She shows that despite some disambiguation by the conventional implicature inherent in the quotative verb 'claim', its function is redundantly explicitated in both languages through strategies which foreground the journalist's judgmental attitude and authoritative positioning.

(2) Anita Fetzer examines the discursive functions and strategic use of fresh quotations in Prime Minister's Questions considering the interdependence between source and formatting on the one hand, and uptake on the other. She demonstrates that quotations fulfil an argumentative function: they may be used to secure discourse common ground, challenge the argumentative coherence and credibility of Other while supporting the construction of argumentative coherence and credibility of Self.

(3) Sonja Kleinke investigates the quoting practices of Wikipedia. The collectively produced and discussed entries, guided by the encyclopedia's edition principles, presuppose a high extent of cooperation between different users based on external sources and hyperlinks. The paper focuses on forms and functions of two highly controversial case studies: the entries on Brexit and Nation, and highlights micro-level (indexical, interpersonal, argumentative, metapragmatic) functions as well as the adaptation of imported text chunks in the overarching structure.

(4) Andreas Musolff explores the contextual constraints and requirements of quoting metaphorical speech and allusions triggered by it in political discourse. He concentrates on the phrase "to have one's cake and eat it" derived from the proverb and its discourse career in the discourse on Brexit, where the phrase was recycled, redefined and ridiculed many times as a characterisation of Britain's position in the "Brexit" negotiations. He shows that quotations of proverbs are more than second-order representations of idiomatic templates but rather serve a wide range of socio-pragmatic purposes.

(5) Nadine Thielemann analyses the breadth and associative power of allusions in Russian casual conversations in their sequential and interactional as well as wider cultural context. She shows how even the most "mutilated" quotations may serve as reference to another (con)text and enable the interlocutors to identify the source, thus adding additional layers of interpretation. The manifold ways in which interlocutors elaborate on allusions by creating fictive discourse and string them jointly together testifies to an amazingly rich common cultural background and interactionally reinforces it at the same time, thus adding to a strong mutually shared feeling of belonging and closeness.

(6) Daniel Weiss examines quotations as a possible vehicle of analogical reasoning. This pairing of form and function raises an important question: why should the "detour" caused by quoting a new voice enhance a type of argumentation that has often been denounced as fallacious? The answer seems to be that it offers additional pragmatic effects (delegitimisation of Other, entertainment, self-staging etc.) that can compensate the deficient argumentative power. The study is mainly based on two diametrically opposed types of quotations from debates in the Russian State Duma: hypothetical utterances (related both to future and past) and proverbs.

(7) Monika Kirner-Ludwig analyses fake quotes as a subtype of pseudo-quoting, scrutinising their defining features / conditions, and their functions in mediated lay political discourse. Particular attention is given to the villainizing of a third party and lying as a communicative activity, including plagiarising. It discusses the contextual conditions of what makes a quote a 
fake or pseudo-quote. The analysis focuses on material associated with fake news having risen since the 2016 US elections, especially a fake quote attributed to Donald Trump on Facebook and the way users negotiate the "truthfulness" of this particular quote.

\section{References}

Austin, John L. 1975. How to Do Things with Words. Cambridge: Cambridge University Press. Brendel, Elke, Jörg Meibauer and Markus Steinbach. 2011. "Exploring the Meaning of Quotation." In Understanding Quotation, ed. by Elke Brendel, Jörg Meibauer and Markus Steinbach, 1-33. Berlin: de Gruyter.

Brown, Penelope and Stephen C. Levinson. 1987. Politeness. Some Universals in Language Usage. Cambridge: Cambridge University Press.

Bublitz, Wolfram. 2015. Introducing Quoting as a Ubiquitous Meta-communicative Act. In Jenny Arendholz, Wolfram Bublitz and Monika Kirner-Ludwig (eds.). The Pragmatics of Quoting Now and Then, 1-26. Berlin/Boston: De Gruyter Mouton.

Fetzer, Anita. 2007. "Reformulation and Common Grounds." In Lexical Markers of Common Grounds, ed. by Anita Fetzer and Kerstin Fischer, 157-197. London: Elsevier.

Fetzer, Anita. 2015. "When you came into office you said that your government would be different': Forms and Functions of Quotations in Mediated Political Discourse". In The Dynamics of Political Discourse: Forms and Functions of Follow-Ups, ed. by Anita Fetzer, Elda Weizman and Lawrence N. Berlin, 245-273. Amsterdam: John Benjamins.

Goffman, Erving. 1981. Forms of Talk. Oxford: Blackwell.

Grice, Herbert Paul. 1975. "Logic and Conversation." In Syntax and Semantics, ed. by Peter Cole and Jerry L. Morgan, 41-58. New York: Academic Press.

Lennon, Paul. 2008. Allusions in the Press. An Applied Linguistic Study. Berlin, New York: De Gruyter.

Levinson, Stephen C. 1988. "Putting Linguistics on a Proper Footing: Explorations in Goffman's Concepts of Participation." In Erving Goffman: Exploring the Interaction Order, ed. by Paul Drew and Anthony Wootton, 161-227. Cambridge: Polity Press.

Oishi, Etsuko and Fetzer, Anita. 2016. "Expositives in Discourse.” Journal of Pragmatics 96: 49-59.

Park, Joseph Sung-Yul and Bucholtz, Mary. 2009. "Public Transcripts: Entextualization and Linguistic Representation in Institutional Contexts." Text \& Talk 5: 485-502.

Schäffner, Christina and Bassnett, Susan (eds.) 2010. Political Discourse, Media and Translation. Newcastle: Cambridge Scholars Publishing.

Searle, John R. 1969. Speech Acts. Cambridge: Cambridge University Press.

Sbisà, Marina. 2002. "Speech Acts in Context." Language and Communication 22(4): 421-436. Tannen, Deborah. 2007. Talking Voices: Repetition, Dialogue and Imagery in Conversational Discourse. Cambridge: Cambridge University Press.

Wilson, Deidre. 2012. "Metarepresentation in Linguistic Communication. In Meaning and Relevance, ed. by Deidre Wilson and Dan Sperber, 230-258. Cambridge: Cambridge University Press.

Witek, Maciej. 2015. "Linguistic Underdeterminacy: A View from Speech Act Theory." Journal of Pragmatics 76: 15-29. 
Yus, Francisco. 2018. "Identity-Related Issues in Meme Communication.” Internet Pragmatics 1(1): 113-133.

contributions

1. Anita Fetzer \& Daniel Weiss, Introduction: How To Do Things With Quotes

2. Elda Weizman, The discursive pattern 'claim+indirect quotation in quotation marks': strategic uses in French and Hebrew online journalism

3. Anita Fetzer, "And I quote": forms and functions of quotations in Prime minister's questions

4. Sonja Kleinke, Wikipedia: quotations at the interface of encyclopedic and participatory practices

5. Andreas Musolff, How (not?) to quote a proverb: the role of figurative quotations and allusions in political discourse

6. Nadine Thielemann, Allusive talk - playing on indirect intertextual references in Russian conversation

7. Daniel Weiss, Analogical reasoning with quotations? A spotlight on Russian parliamentary discourse

8. Monika Kirner-Ludwig, Creation, dissemination and uptake of fake-quotes in lay political discourse on Facebook and Twitter 